\title{
Sex and hand-preference factors in psychomotor reminiscence and performance
}

\author{
JOAN M. DIETRICH and R. B. PAYNE \\ University of Georgia, Athens, Georgia
}

\begin{abstract}
Effects of sex, handedness, and hand used in practice (preferred or nonpreferred) on reminiscence in a rotary tracking task were investigated in 80 subjects. As in a comparable study of mirror tracking (Wild \& Payne, 1983), the female tendency to reminisce more than males on rotary pursuit was conditional upon the use of the preferred hand, whether right or left. However, the two tasks yielded several noteworthy differences in the effects of these variables on performance levels and secular trends. Implications of results for reminiscence theory were explored.
\end{abstract}

Several recent studies of young adults showed that females reminisced more than males did in tasks that required continuous monitoring and responding (Coppage \& Payne, 1981; Hsu \& Payne, 1979; Huang \& Payne, 1975; McBride \& Payne, 1979, 1980). These results were rationalized in terms of Hull's (1943) concept of reactive inhibition $\left(I_{R}\right)$ by supposing that females generated more $I_{R}$ during the prerest trials than males did and that, having accumulated more, they released more across resta view strongly supported by several tests of implications (Dietrich \& Payne, 1983; McBride \& Payne, 1979, 1980; Shaffer \& Payne, 1982). Moreover, the female tendency to generate greater amounts of $I_{R}$ appeared to depend on concentration levels of estrogenic hormones (Brown, Forand, \& Payne, 1984; Lamson-McBride \& Payne, 1981; Wells \& Payne, 1979), the adrenergic properties of which were thought to promote more vigorous responding (Vogel, Broverman, \& Klaiber, 1971), and hence also more $I_{R}$ as defined by Hull. Known collectively as the estrogen activation hypothesis, these ideas accounted not only for the sex difference in the reminiscence tendencies of young adults, but also for the absence thereof in elderly subjects (Wright \& Payne, 1985).

Given the foregoing background of well-articulated fact and theory, it was somewhat startling to discover that the sex difference in reminiscence was conditional upon the use of the preferred hand. Noting that all previous studies of this difference had used right-handed subjects who practiced with their right hands, Wild and Payne (1983) employed mirror tracking to measure reminiscence in the eight combinations of sex, handedness, and hand actually used in practice (preferred or nonpreferred). They found that women who practiced with the preferred hand, whether right or left, reminisced more than men, whereas women who practiced with the nonpreferred hand and men who practiced with either hand reminisced essentially alike.

The evidence for interaction of sex and preference effects on reminiscence added a new and unsuspected

Requests for reprints should be sent to R. B. Payne, Department of Psychology, University of Georgia, Athens, GA 30602. dimension to the interpretational problem and raised many questions for further study. Foremost among these questins was whether the interaction effect was characteristic of other tasks in the tracking domain, for it is obvious that theoretical treatment is contingent upon the generality of the finding. Inasmuch as the sex difference had also been found in rotary tracking (Huang \& Payne, 1975; McBride \& Payne, 1980), we decided to replicate the experimental treatments of the Wild and Payne (1983) study with the rotary pursuit task as the test vehicle.

\section{METHOD}

\section{Subjects}

The experimental sample consisted of 80 Caucasian subjects ( 40 of each sex) drawn by consent from introductory psychology classes and awarded course credit points for participation. Half the subjects of each sex were right-handed, and half were left-handed, as determined by selfdeclaration, name-signing on separate occasions, and a brief inventory of manipulative preferences. Ages ranged from 18 to 23 years, with a mean age of 19 for males and 19.1 for females.

\section{Task}

A copy of the USAF SAM Rotary Pursuit Test, Model CM 803B2, as described by Melton (1947), served as the test vehicle. The task required the subjects to track a penny-sized silver target as it rotated clockwise at $60 \mathrm{rpm}$. Time on target was recorded to the nearest $.01 \mathrm{sec}$ for each 60 -sec trial.

\section{Procedure}

Ten of the 20 subjects in each combination of sex and handedness were assigned without bias to practice with the right hand, whereas the remaining 10 subjects were assigned to practice with the left hand. After instruction and demonstration, all subjects executed a nine-trial sequence of $3 \mathrm{~min}$ of continuous practice (Block 1, Trials 1-3), 3 min of rest, $3 \mathrm{~min}$ of continuous practice (Block 2, Trials 4-6), $3 \mathrm{~min}$ of rest, and 3 min of continuous practice (Block 3, Trials 7-9)

\section{RESULTS}

\section{Reminiscence}

Two reminiscence scores were derived for each subject by subtracting the scores made on Trials 3 and 6 from those made on Trials 4 and 7 , and the mean of the two scores was used as the dependent measure. The 80 means were then subjected to a variance analysis in which sex, handedness, and hand used in practice (preferred or non- 
Table 1

Effects of Sex and Practice Hand on Mean Reminiscence in Mirror-Tracking and Rotary-Pursuit Tasks

\begin{tabular}{|c|c|c|c|c|}
\hline & \multicolumn{2}{|c|}{ Mirror Tracking } & \multicolumn{2}{|c|}{ Rotary Pursuit } \\
\hline & $\mathrm{P}$ & $\overline{\mathrm{P}}$ & $\mathrm{P}$ & $\overline{\mathbf{P}}$ \\
\hline Male & 4.01 & 4.72 & 8.83 & 7.88 \\
\hline Female & 8.24 & 4.85 & 10.73 & 8.35 \\
\hline
\end{tabular}

preferred) provided the main effects. Inasmuch as the purpose of the analysis was to see whether simple effects obtained in rotary pursuit resembled those in mirror tracking, mean reminiscence values were computed for the four combinations of sex and hand use in practice $(\mathrm{P}$ or $\overline{\mathrm{P}})$, and relevant contrasts were examined for statistical significance.

The subclass means for both tasks are shown in Table 1 . One can see here that the two tasks yielded similar patterns of means in that females who practiced with their preferred hands reminisced more than the subjects in all other combinations of sex and preference. Analyses of mirror-tracking results showed that the mean of the FP group (female, preferred hand), was significantly higher than that of an equally weighted linear combination of the other means $[\mathrm{t}(72)=4.26, \mathrm{p}<.001$ (single tail)], and this was also the case in rotary pursuit $[\mathrm{t}(72)=2.43, \mathrm{p}<$ .01 (single tail)]. Additional contrasts within the two tasks also supported the impression of intertask similarity of outcomes. For one example, FP $>$ F $\bar{P}$ (mirror tracking) $[\mathrm{t}(72)=3.18, \mathrm{p}<.001$ (single tail) $]$, and FP $>\mathrm{FP}$ (rotary pursuit) $[\mathrm{t}(72)=1.98, \mathrm{p}<.05$ (single tail)]. For another, FP > MP (mirror tracking) $[\mathrm{t}(72)=3.96, \mathrm{p}<$ .001 (single tail)], and FP > MP (rotary pursuit) [t(72) $=1.58, p \approx .06$ (single tail)]. Finally, in order to establish consistency with previous results on right-handed subjects who practiced with their right hands, we note that females out-reminisced males in both mirror tracking [means $=7.36$ vs. $4.13 ; \mathrm{t}(72)=2.14, \mathrm{p}<.025$ (single tail)] and rotary pursuit [means $=12.53$ vs. $8.42 ; \mathrm{t}(72)$ $=2.42, \mathrm{p}<.01$ (single tail)].

What emerges from the foregoing comparisons is a clear impression of similarity of task outcomes despite the marginal significance of the FP-MP difference. The generally lower significance values characteristic of the rotary pursuit data are due to the last two cases of the sample, both of which fell in the female LL category (i.e., lefthanded, left hand used) and whose $\mathrm{z}$ values were -1.84 $(p \approx .03)$ and $-2.86(p \approx .004)$. The primary effect of these scores was to attenuate the significance of the FP-MP contrast by reducing the mean difference and inflating the error term. When the two scores were excluded from the analysis, tests of simple effects based on an unweighted means analysis of variance supported all the foregoing contrasts at satisfactory levels of significance $(\mathrm{p} \leq .025)$.

\section{Tracking Proficiency}

Whereas mirror-tracking and rotary-pursuit tasks yielded uniformly comparable outcomes with regard to the effects of sex, handedness, and hand usage on reminiscence, they provided a curious mixture of similar and dissimilar results with regard to the effects of these variables on performance levels and secular trends. In order to compare outcomes in the two tasks, each set of 720 scores was subjected to a mixed-model variance analysis in which sex $(\mathrm{S})$, handedness $(\mathrm{H})$, and hand used in practice $(\mathrm{P})$ provided the main between-subjects effects, and blocks of practice $(\mathrm{B})$ and trials within blocks $(\mathrm{T})$ provided the main within-subjects effects. Of the 31 sources of variation (main effects and interactions), 10 were significant $(p \leq .05)$ in one task or the other. These outcomes are summarized in Table 2.

Mirror tracking. Oddly enough, none of the main between-subjects effects and none of the between-subjects sources of interaction was significant. As one would expect, the block effect was significant, the block means increasing as a negatively accelerated function of their ordinal position. Moreover, the slope of the block function was steeper for $\mathrm{P}$ subjects than for $\overline{\mathrm{P}}$ subjects (see $\mathrm{PB}$ in Table 2). The block means for $P$ subjects were 14.44 , 22.91 , and $27.65 \mathrm{sec}$, and those for $\overline{\mathrm{P}}$ subjects were $14.18,20.17$, and $24.45 \mathrm{sec}$. Thus, preferred-hand practice conferred only a slight and insignificant advantage on Block $1(.26 \mathrm{sec})$, but this advantage increased monotonically to $3.2 \mathrm{sec}$ on Block 3 [t(72) $=1.84, \mathrm{p}<.05$ (single tail)]. No other effects involving blocks were significant. The main effect of trials collapsed across blocks was not significant, but there was a significant interaction of sex and trial effects (ST) in which males gained across trials $(18.92,19.53$, and $20.36 \mathrm{sec})$, whereas females lost $(22.03,21.3$, and $21.65 \mathrm{sec})$. This result is commonly found in mirror tracking under these practice conditions (McBride \& Payne, 1979), and it is one of the empirical supports of $I_{R}$ theory as applied to the sex difference in reminiscence. Finally, there was a significant interaction of trial and block effects (BT) in which the means increased across trials in Block 1, held about even in Block 2, and decreased across trials in Block 3.

Rotary pursuit. Unlike mirror-tracking performance, rotary-pursuit performance was significantly affected by

Table 2

Summary of Significant Sources of Variation in Mirror-Tracking (MT) and Rotary-Pursuit (RP) Performance

\begin{tabular}{|c|c|c|c|c|c|}
\hline \multirow[b]{2}{*}{ Source } & \multirow[b]{2}{*}{ df } & \multicolumn{2}{|c|}{ MT } & \multicolumn{2}{|c|}{ RP } \\
\hline & & $\mathrm{F}$ & $\mathrm{p}<$ & $\mathrm{F}$ & $\mathrm{p}<$ \\
\hline$S$ & 1,72 & \multicolumn{2}{|c|}{ n.s. } & 13.86 & .001 \\
\hline $\mathrm{H}$ & 1,72 & \multicolumn{2}{|c|}{ n.s. } & 8.25 & .01 \\
\hline$P$ & 1,72 & \multicolumn{2}{|c|}{ n.s. } & 25.00 & .001 \\
\hline $\mathrm{HP}$ & 1,72 & \multicolumn{2}{|c|}{ n.s. } & 11.41 & .005 \\
\hline B & 2,144 & 280.74 & .001 & 456.63 & .001 \\
\hline SB & 2,144 & \multicolumn{2}{|c|}{ n.s. } & 9.10 & .001 \\
\hline PB & 2,144 & 5.00 & .01 & 12.82 & .001 \\
\hline $\mathrm{T}$ & 2,144 & \multicolumn{2}{|c|}{ n.s. } & 13.36 & .001 \\
\hline ST & 2,144 & 5.37 & .01 & \multicolumn{2}{|c|}{ n.s. } \\
\hline BT & 4,288 & 8.24 & .001 & 28.88 & .001 \\
\hline
\end{tabular}

Note-The 21 unlisted sources were nonsignificant for both tasks. 
sex, handedness, and hand used in practice $(\mathrm{P}$ or $\overline{\mathrm{P}})$. Each of these effects, however, was correlated with the effects of one or more of the other variables.

With respect to the sex effect, males outperformed females, as commonly found (Noble, 1978), but the female disadvantage decreased monotonically as a function of the ordinal position of practice blocks (see SB in Table 2). The SB means were: $\mathrm{MB} 1=13.15, \mathrm{FB} 1=7.03$, $\mathrm{MB} 2=21.96, \mathrm{FB} 2=15.94, \mathrm{MB} 3=25.49$, and FB3 $=22.9 \mathrm{sec}$. At first glance, this interaction might suggest differential learning rates in favor of females. Further inspection of simple sex effects, however, showed that nearly all the SB interaction was due to a $2.82-\mathrm{sec}$ net gain by females across the second rest period. Moreover, McBride and Payne (1980) showed that the sexes gained essentially alike when practice was distributed (intertrial interval $=40 \mathrm{sec}$ ), but that males outgained females when practice was continuous. Thus, the present result seems better understood as another example of greater female profit from the rest intervals between blocks of practice.

With regard to the handedness effect $(\mathrm{H})$, right-handers outperformed left-handers (means: $\mathrm{R}=19.64 \mathrm{sec}, \mathrm{L}=$ $15.85 \mathrm{sec}$ ), but only when the right-handers used their preferred hands (see HP in Table 2). The HP means were: RP (i.e., right-handers using their preferred hands) = $25.15, R \bar{P}=14.12, L P=16.92$, and $L \bar{P}=14.78$ sec. No significant differences were found among the last three combinations. The superiority of the RP group was due in part to a net gain of $2.04 \mathrm{sec}$ across rest, perhaps because higher responsivity generated more $I_{R}$, and hence more reminiscence. The residual difference can be understood in terms of the clockwise rotation of the target, which is highly compatible with the RP combination but less so with any combination involving left preference or usage (Milisen \& Van Riper, 1939). Counterclockwise target rotation should favor the LP combination above all others.

As in mirror tracking, the block effect in rotary pursuit was significant, and the slope of the block function was steeper for $\mathrm{P}$ subjects than for $\overline{\mathrm{P}}$ subjects (see $\mathrm{PB}$ in Table 2). The block means for $P$ subjects were 12.08 , 22.52 , and $28.52 \mathrm{sec}$, whereas those for $\overline{\mathrm{P}}$ subjects were $8.11,15.37$, and $19.87 \mathrm{sec}$. Thus, preferred-hand practice conferred a 3.97-sec advantage on Block $1[\mathrm{t}(72)=$ $3.38, \mathrm{p}<.001$ ], which increased monotonically to 8.65 sec on Block $3[t(72)=5.59, \mathrm{p}<.001]$. Although the two tasks were similar with respect to the PB interaction, there is one noteworthy difference. Whereas preferredhand usage was advantageous across all practice blocks in rotary pursuit, it did not become so in mirror tracking until Block 3, and even then at only a marginal level of significance.

Finally, we round out the summary of results by noting that the significant trials-within-blocks effect in rotary tracking was orthogonal to the sex effect-a finding at variance with that observed in mirror tracking and with that reported for rotary tracking by Huang and Payne (1975).
There was a significant interaction of trial and block effects wherein, as in mirror tracking, mean performance increased across trials in Block 1 and decreased across trials in Block 3.

\section{DISCUSSION}

It is clear that the sex difference in reminiscence on the pursuit rotor is conditional upon the use of the preferred hand, just as it was in mirror tracking. Any credible interpretation of reminiscence must therefore account not only for the foregoing outcomes, but also for the fact that estrogenic hormone levels contribute to the difference, as noted earlier (Brown et al., 1984). Although other theoretical accounts of reminiscence might be modified for this purpose (e.g., the consolidation theory of Eysenck \& Frith, 1977), we propose that these phenomena can be rationalized in terms of Hull's (1943) concepts of habit, drive, and reactive inhibition.

Whatever else the concept of hand preference may mean, it implies a lifelong differential accumulation of perceptual-motor habits by the two hands. These hand-related populations of habits can be regarded as coordination inventories upon which a subject draws in order to execute some new task; indeed, this is partly what is meant by the transfer factor " $T$ " in Noble's (1978) conceptualization of motor learning. If we now accept the premise that the strength of hand preference is substantially greater in females than in males, as proposed by Collins (1977) and at least partially confirmed by Porac and Coren (1981, pp. 39, 106), we arrive at the logical possibility that a given level of task motivation will tend to promote female preferred-hand responsivity more than that of all other combinations of sex and hand preference. One can suppose further that this enhancement tendency combines synergistically with drive-like effects arising from the adrenergic properties of estrogenic hormone concentrations (Vogel et al., 1971) which, for randomly selected females, are more likely than not to be above nadir levels (Nocenti, 1968). The terminal consequence of increased responsivity in the female preferred hand is a larger accumulation of reactive inhibition, the subsidence of which across the rest interval is manifested as greater reminiscence vis-à-vis that of all other combinations of sex and hand preference.

Tenuous as the foregoing construction may seem, it is logically consistent with $I_{R}$ theory and with the various sets of empirical data cited. Moreover, it offers at least two implications that are amenable to experimental test. For one, females tested at the nadirs of their estrogen cycles should show a reduced, perhaps negligible, hand-preference effect on reminiscence, similar to that of the males in the present study. For another, females tested under the influence of contraceptive medication should likewise exhibit a small if not negligible hand-preference effect. Indeed, we already know that each of these conditions reduces reminiscence in right-handed subjects who practice with their preferred hands (Brown et al., 1984; Lamson-McBride \& Payne, 1981; Wells \& Payne, 1979), but we do not yet know what effects they have on reminiscence in the nonpreferred hand. These and kindred studies are now underway.

\section{REFERENCES}

Brown, I. S., Forand, A. Q., \& Payne, R. B. (1984). Hormonal influences on psychomotor reminiscence. Perceptual and Motor Skills, 58, 383-389.

Collins, R. L. (1977). Toward an admissible genetic model for the inheritance of the degree and direction of asymmetry. In S. Harnard, R. W. Doty, J. Jaynes, L. Goldstein, \& G. Krauthamer (Eds.). Lateralization in the nervous system. New York: Academic Press.

Coppage, S. J., \& PAYNe, R. B. (1981). An experimental test of current theories of psychomotor reminiscence. Perceptual and Motor Skills, 52, 343-352.

Dietrich, J. M., \& PAYNe, R. B. (1983). Psychomotor reminiscence as a function of sex and amount of prerest practice. Bulletin of the Psychonomic Society, 21, 377-380.

EYSENCK, H. J., \& FRITH, C. D. (1977). Reminiscence, motivation, and personality. New York: Plenum. 
Hsu, S. H., \& PAYNe, R. B. (1979). Effector localization and transfer of reactive inhibition. Journal of Motor Behavior, 11, 153-158.

HuANG, K. L., \& PAYNE, R. B. (1975). Individual and sex differences in reminiscence. Memory \& Cognition, 3, 252-256.

Hull, C. L. (1943). Principles of behavior. New York: AppletonCentury-Crofts.

Lamson-McBride, E., \& Payne, R. B. (1981). Psychomotor reminiscence and the menstrual cycle. Bulletin of the Psychonomic Society, 17, 97-100.

McBride, D. K., \& PAYNe. R. B. (1979). Psychomotor reminiscence as a function of sex and length of rest period. Journal of Motor Behavior, 11, 59-64.

McBRIDE, D. K., \& PAYNE, R. B. (1980). The sex difference in rotary pursuit performance: Aptitude or inhibition? Journal of Motor Behavior, 12, 270-280.

Melton, A. W. (Ed.). (1947). Apparatus tests (AAF Aviation Psychology Program, Research Report No. 4). Washington, DC: U.S. Government Printing Office.

MilisEN, R., \& VAN RIPER, C. (1939). Differential transfer of training in a rotary activity. Journal of Experimental Psychology, 24, 640-646.

Noble, C. E. (1978). Age, race, and sex in the learning and performance of psychomotor skills. In R. T. Osborne, C. E. Noble, \& N. Weyl (Eds.), Human variation: The biopsychology of age, race, and sex. New York: Academic Press.
NocentI, M. R. (1968). Reproduction. In V. B. Mountcastle (Ed.), Medical physiology. St. Louis: Mosby.

Porac, C., \& COREN, S. (1981). Lateral preferences and human behavior. New York: Springer.

Shaffer, G. S., \& PAYNE, R. B. (1982). Contralateral transfer of reactive inhibition as a function of sex and interpolated rest. Perceptual and Motor Skills, 54, 979-985.

Vogel, W., Broverman, D. M., \& Klaiber, E. L. (1971). EEG responses in regularly menstruating women and in amenorrheic women treated with ovarian hormones. Science, 172, 388-391.

Wells, K. C., \& Payne, R. B. (1979). Psychomotor reminiscence as a function of gonadal steroid hormone variation. Bulletin of the Psychonomic Society, 14, 197-200.

WiLD, H. M., \& PAYNe, R. B. (1983). Effects of hand preference on the sex difference in psychomotor reminiscence. Perceptual and Motor Skills, 57, 1171-1175.

Wright, B. M., \& PAYNe, R. B. (1985). Effects of aging on sex differences in psychomotor reminiscence and tracking proficiency. Journal of Gerontology, 40, 179-184.

(Manuscript received for publication January 28, 1985.) 